\title{
Antioxidant Potential of Extracts from Processing Residues from Brazilian Food Industries
}

\author{
Natália Mezzomo, Daniela A. Oliveira, Sandra R. S. Ferreira* \\ EQA-CTC/UFSC, Chemical and Food Engineering Department, Federal University of Santa Catarina, Florianópolis, Brazil. \\ Email: *sandra@enq.ufsc.br
}

Received April $8^{\text {th }}, 2013$; revised May $8^{\text {th }}, 2013$; accepted May $15^{\text {th }}, 2013$

Copyright (C) 2013 Natália Mezzomo et al. This is an open access article distributed under the Creative Commons Attribution License, which permits unrestricted use, distribution, and reproduction in any medium, provided the original work is properly cited.

\begin{abstract}
The objective of this work was to estimate the antioxidant potential of the extracts from pink shrimp residue and red grape pomaces (Merlot and Syrah varietals), evaluated according to its antioxidant activity with different analytical methods, associating these properties with the chemical composition of the extract and, as a consequence, with the extraction procedure. The shrimp residue was pre-treated combining cooking, drying, and milling, whereas the grape pomaces were dried and ground. The shrimp residue extracts were obtained by Soxhlet (SOX) and by maceration using hexane (Hx), hexane: isopropanol (50:50) (Hx:IPA), isopropanol, ethanol (EtOH) and acetone as solvents; by ultrasonic maceration (UME) with EtOH; by cold and hot oil extraction with soy and sunflower oils; and by Supercritical Fluid Extraction (SFE) with pure $\mathrm{CO}_{2}(100-300$ bar; 313.15 - $333.15 \mathrm{~K})$ and with co-solvent (Hx: IPA and sunflower oil at 2\%). The grape pomaces extracts were obtained by SOX using EtOH, ethyl acetate (EtOAc) and Hx; UME with water $\left(\mathrm{H}_{2} \mathrm{O}\right)$, EtOH, EtOAc and $\mathrm{Hx}$; and by SFE performed with pure $\mathrm{CO}_{2}(150-300$ bar; $323.15-333.15 \mathrm{~K})$ and with cosolvent (EtOH at 15\%). The antioxidant activity was determined by the DPPH free radical scavenging procedure and by the $\beta$-carotene bleaching method. Higher antioxidant activities in shrimp residue extracts were observed by the $\beta$-carotene bleaching method in alcoholic and cetonic extracts, among the low pressure extraction methods, while for the SFE, the higher activities were achieved by the extracts obtained at elevated pressures. For the grape pomaces extracts, the best results were obtained by the DPPH method from the low pressure extractions proceeded with EtOH. The SFE with Merlot pomace at $323.15 \mathrm{~K} / 150 \mathrm{bar}$ (the lowest temperature and pressures tested) presented the best antioxidant activity by the $\beta$-carotene bleaching.
\end{abstract}

Keywords: Supercritical Fluid Extraction; Shrimp Residue; Grape Pomace

\section{Introduction}

According to the Food and Agriculture Organization of the United Nations [1], the worldwide capture production of marine crustaceans reached, in 2007, the total of 5840 thousands ton. The use of shrimp processing waste represents a potential source of food ingredients and other additives and the use of industrial wastes is not only economic, but also environmental important [2]. The marine wildlife is rich in high quality fatty acids with proved biological value, being presented in industrial and commercial residues of the marine products processing. The marine fishes and crustaceans are important constituents from human diet and possess the highest source of essential polyunsaturated fatty acids (PUFAs), especially from the groups of eicosapentaenoic (EPA) and docosahexa-

\footnotetext{
${ }^{*}$ Corresponding author.
}

noic (DHA) from $\omega-3$ family. The scientific researches focusing on this fatty acids have been intensified lately because they are involved in prevention and cure of cardiovascular and inframmatory diseases [3].

The astaxanthin is the main carotenoid present in aquatic animals, such as crab, lobster, and shrimp. This pigment presents protection against free radicals, lipid peroxidation, oxidative damage to the LDL-cholesterol, oxidation of essential PUFAs, UV-light, among others [4]. Otherwise, synthetic antioxidants such as butylated hydroxyanisole (BHA) and butylated hydroxytoluene (BHT) are generally used in fat and oil industries. However, scientific works have proved that these substances can cause adverse effects in animals such as hemorrhages in the pleural and peritoneal cavities [5] and extensive cell proliferation in the lung with biochemical changes, acting as a promoter of adenoma development [6]. The con- 
cern related to these adversities has enhanced, in recent years, the search for natural antioxidants with the same efficiency and function of the synthetic ones [7].

According to the wine industry, each 100 liters of red wine produced engenders $17 \mathrm{~kg}$ of grape pomace, composed by seed, skin and stem, usually disposed as compost. This residue still contains high levels of phenolic compounds many of them reported as antioxidants $[8,9]$. But the relatively high level of phenolic compounds in the grape pomace is a problem for its application as fertilizer because of their inhibition of germination properties [10]. On the other hand, grape phenolic compounds are associated to antioxidant activity and health benefits such as prevention of cancer and cardiovascular diseases $[8,9,11,12]$. Thus, the possibility of converting the enormous amount of this residue generated by winery Industry around the world into add-valued products, promotes studies using the grape pomace to obtain functional ingredients.

The aim of this work was the estimation of the antioxidant potential of extracts from two important residues of the food industry: the pink shrimp (Penaeus brasiliensis and Penaeus paulensis) residue and the Merlot and Syrah (Vitis vinifera) pomaces.

\section{Material and Methods}

\subsection{Sample Preparation}

The pink shrimp ( $P$. brasiliensis and $P$. paulensis) residue (waste from shrimp processing) was composed essentially by head, carapace, and tail. The residue was provided by Peixaria Nelson Santos (Florianópolis, Santa Catarina, Southern Brazil), sited at the local public market. The raw material was obtained from the unpeeling of the cultivated shrimp collected in May 2010, which represents the high production season of the region. The shrimp residue was pre-treated by combining the process of cooking, drying and milling, as designed by Mezzomo et al. [2]. The pink shrimp processing waste was submitted to a quick cooking by double boiler in water at $373.15 \mathrm{~K}$ during $10 \mathrm{~min}$, followed by drying at $333.15 \mathrm{~K}$ for 5 hours (when using the extraction techniques: Soxhlet, maceration, ultrasonic maceration, and oil extraction) or 10 hours (when using supercritical extraction) in a oven with air circulation (DL-SE, DeLeo). Finally, the samples were grounded in a domestic blender (LiqFaz, Wallita) with mass and time pre-determined.

The pressed grape pomaces derived from Merlot and Syrah (Vitis vinifera) wine production, were provided by two wineries from Miolo Wine Group. The Syrah pomace, vintage 2008 from winery located in Vale do São Francisco-Bahia, Brazil, presented initial moisture content of $56 \% \pm 2 \%$ (wet base) and the Merlot pomace, vintage 2009 , provided by the winery from Vale dos Vin-
hedos-Rio Grande do Sul, Brazil, was received with initial moisture content of $64 \% \pm 1 \%$ (wet base). The grape residues were dried at $32^{\circ} \mathrm{C}$ in a forced air circulation oven (De Leo, Model A3 CARF, RS, Brazil) up to approximately $10 \%$ moisture content $(10.1 \% \pm 0.3 \%$ for Syrah pomace, reached after $20 \mathrm{~h}$ drying, and $10 \% \pm 1 \%$ for Merlot pomace, reached after $21.5 \mathrm{~h}$ drying). The total moisture content was assessed by maintaining the samples in a stove at $105^{\circ} \mathrm{C}$ until constant weight. Dried samples were grounded in a knife mill (De Leo, Porto Alegre/RS, Brasil) and the particle size was classified in sieve separator (Bertel Indústria Metalúrgica Ltda., Caieiras/SP, Brasil). The particle fraction of $-20 /+32$ Mesh was selected to proceed the extractions.

\subsection{Extraction Protocols}

The maceration (MAC) method consisted in a cold extraction of the pre-treated shrimp residue in organic solvent to avoid thermal degradation. The procedure was performed according to Mezzomo et al. [2]. Briefly, it consists of transferring $25 \mathrm{~g}$ of the shrimp residue sample into $100 \mathrm{~mL}$ of selected organic solvent for five days at room temperature, with light protection and one daily manual agitation. Each extraction was performed in triplicate using the solvents hexane $(\mathrm{Hx})$, ethanol $(\mathrm{EtOH})$, acetone (Ac), isopropanol (IPA), and the binary mixture Hx:IPA (50:50, v/v). The extracts were concentrated under vacuum in a rotatory evaporator.

The Soxhlet extraction (SOX) was performed in triplicate and based on the procedure described by Campos et al. [13]. Briefly, the raw materials (5 g) were packed inside a cartridge and transferred to a $250 \mathrm{~mL}$ extractor device and submitted to 8 hour recycling extraction with $150 \mathrm{~mL}$ solvent at boiling temperature. The extraction was performed with the following solvents (P.A., Nuclear, CAQ Ind. e Com. LTDA., Brazil): Hx, EtOH, Ac, IPA and Hx:IPA (50:50, v/v) for the shrimp residue; and $\mathrm{EtOH}$, ethyl acetate (EtOAc) and Hx for the grape residues. The extracts were concentrated under vacuum in a rotatory evaporator.

For the shrimp residue the ultrasonic maceration (UME) was performed in triplicate and adapted from Mezzomo et al. [2], using EtOH as solvent. Briefly, it consists of adding $5 \mathrm{~g}$ of raw material in $150 \mathrm{~mL}$ of $\mathrm{EtOH}$, maintaining the solution into an ultrasound apparatus (UtraCleaner 700, $55 \mathrm{kHz}, 40 \mathrm{VA}$, Unique) for 10 min. The extract was separated from the raw material by centrifugation (Q222T, Quimis) at $2000 \mathrm{~g}$ for $20 \mathrm{~min}$ and concentrated under vacuum in a rotatory evaporator.

For the wine residues the UME was conducted using 3 $\mathrm{g}$ of pre-treated pomaces and $50 \mathrm{~mL}$ of solvent placed inside a glass balloon connected to a condenser. The extraction was performed in duplicate at room temperature during 30 min, using water $\left(\mathrm{H}_{2} \mathrm{O}\right)$, EtOH, EtOAc and $\mathrm{Hx}$. 
The extract was separated from the raw material by filtration and concentrated under vacuum in a rotatory evaporator.

The extraction method using vegetable oil as solvent was classified according to the solvent temperature and oil type. The cold extraction (OilC) and the hot extraction $(\mathrm{OilH})$ with soy or sunflower oil were performed according to the procedure presented by Sachindra and Mahendrakar [14], in triplicate. Briefly, the method consists of mixing $10 \mathrm{~g}$ of raw material with $40 \mathrm{~mL}$ of vegetable oil (soy or sunflower oil) in a $250 \mathrm{~mL}$ flask (light protected), submitted to hot plates with $2 \mathrm{~h}$-agitation period at room temperature $(\mathrm{OilC})$ or at $343.15 \mathrm{~K}(\mathrm{OilH})$. Further, the oil extracts were recovered by cellulose filtration.

The supercritical fluid extractions (SFE) were performed in a dynamic extraction unit [15] using $99.9 \%$ pure $\mathrm{CO}_{2}$ delivered at pressure up to $60 \mathrm{bar}$ (White Martins). A co-solvent pump (Constametric, 3200, EUA), was connected to the extraction line in order to supply the modifier (pure organic solvent, mixture or vegetable oil at high-pressure) at pre-established flow rate, to mix with $\mathrm{CO}_{2}$ flow before the extraction vessel. The extraction procedure [16], consisted of placing a fixed mass inside the extractor cell to form the particles fixed bed, followed by the control of the process variables (temperature and pressure). The extraction was then performed and the solute collected in amber flasks and weighed on an analytical balance (OHAUS, Model AS200S, NJUSA).

The SFE assays from shrimp residue used $16 \mathrm{~g}$ of pretreated shrimp residue to form the fixed bed and applied an extraction time of $180 \mathrm{~min}$. These assays were divided into 2 groups: a) pure $\mathrm{CO}_{2}$ assays, using carbon dioxide as solvent and at the conditions of $313.15-333.15 \mathrm{~K}$ and $200-300$ bar at a constant solvent flow rate of $13.3 \pm 0.8$ $\mathrm{g} / \mathrm{min}$; b) the co-solvent assays, where the hexane: isopropanol solution $(50: 50, \mathrm{v} / \mathrm{v})$ and sunflower oil was mixed with supercritical $\mathrm{CO}_{2}$, at concentrations of $2 \%(\mathrm{w} / \mathrm{w})$, according to results from Mezzomo et al. [17] (no significant increase on extraction yield when co-solvent concentration enhanced from $2 \%$ to $5 \%$ ). This group of assays was performed at $333.15 \mathrm{~K}$ and 300 bar.

The grape pomaces SFE assays applied a constant $\mathrm{CO}_{2}$ flow rate of $13.3 \pm 0.8 \mathrm{~g} / \mathrm{min}$ during $240 \mathrm{~min}$ and the fixed bed was formed with $25 \mathrm{~g}$ of pre-treated material. The conditions of pressures $(\mathrm{P})$ ranging from 150 to 300 bar and temperatures $(\mathrm{T})$ of $323.15 \mathrm{~K}$ and $333.15 \mathrm{~K}$ were applied for the Merlot pomace, while the extraction with the Syrah pomace was conducted at $250 \mathrm{bar} / 333.15 \mathrm{~K}$. The same condition was also used for Merlot pomace to evaluate the influence of the addition of co-solvent (ethanol) to the SFE in concentrations of $12.5 \%, 15 \%$ and $17.5 \%$.
In the case of the organic solvent solution, it was separated from the extract at reduced pressure by evaporating the solvents used in a rotary evaporator (Fisatom, 802 , Brazil), with vacuum control.

\subsection{Antioxidant Potential}

The free radical scavenging activity of extracts was evaluated using the 1,1-diphenyl-2-picrylhydrazil (DPPH) radical scavenger method. Briefly, the extracts was mixed with a $0.3 \mathrm{mM}$ of DPPH ethanol solution to give final concentrations of 5, 50,100,250,500 and $1000 \mu \mathrm{g} / \mathrm{mL}$ of DPPH solution in the case of shrimp residue and 25 , $50,125,250,500,750$ and $1000 \mu \mathrm{g} / \mathrm{mL}$ of DPPH solution in the case of grape pomaces. After $30 \mathrm{~min}$ at room temperature, the absorbance values were measured at 517 $\mathrm{nm}$ converted into percentage of antioxidant activity (\% AA). This activity was also expressed as the effective concentration at $50 \%\left(\mathrm{EC}_{50}\right)$, i.e., the concentration of the solution required to give a $50 \%$ decrease in the absorbnance of the test solution compared to a blank solution [18]. The result data for DPPH assays were obtained considering the mean value of triplicate assays.

The antioxidant activity was also evaluated by the $\beta$ carotene/linoleic acid bleaching method. In this method a model system made of $\beta$-carotene and linoleic acid undergoes a rapid discoloration in the absence of an antioxidant. The free linoleic acid radical is formed upon a hydrogen reduction by the $\beta$-carotene molecules, changing its color [19]. The $\beta$-carotene bleaching rate was determined by the difference in absorbance $(470 \mathrm{~nm})$ values at time intervals between 0 at $120 \mathrm{~min}$. The antioxidant activity from the $\beta$-carotene/linoleic acid system was carried out according to the method described by Matthäus [19], using the different residues extracts in an ethanolic solution at $1667 \mu \mathrm{g} / \mathrm{mL}$.

\subsection{Statistical Analysis}

The results of the antioxidant activity were statistically evaluated by a one-way analysis of variance (ANOVA), using the statistical package Statistica for Windows. The significant differences at level of $5 \%$ were analyzed by Tukey test.

\section{Results and Discussion}

\subsection{Antioxidant Activity of Shrimp Residue Extracts}

The antioxidant activity (\%AA) results, determined by the free radical scavenging (DPPH) and by the $\beta$-carotene bleaching methods, for the shrimp residue extracts are showed in Table 1.

The extracts obtained by low pressure operations that 
Table 1. Antioxidant activity (\%AA) and effective concentration at $50 \%\left(\mathrm{EC}_{50}\right)$ obtained by the free radical scavenging activity method (DPPH) of shrimp (P. brasiliensis and $P$. paulensis) residue extracts.

\begin{tabular}{|c|c|c|c|}
\hline Extraction method ${ }^{\mathrm{a}}$ & Solvent ${ }^{\mathbf{b}}$ & $\% \mathbf{A A}^{\text {cd }}$ & $\mathrm{EC}_{50}(\mu \mathrm{g} / \mathrm{mL})^{\mathrm{ce}}$ \\
\hline SOX & $\mathrm{Hx}$ & $4.0 \pm 0.3^{1}$ & $13466 \pm 1014^{8}$ \\
\hline SOX & HxIPA & $18.1 \pm 0.3^{5,6}$ & $2778 \pm 65^{5,6}$ \\
\hline SOX & IPA & $9.0 \pm 0.1^{2,3}$ & $5314 \pm 58^{7,8}$ \\
\hline SOX & $\mathrm{EtOH}$ & $29.6 \pm 0.9^{7,8}$ & $1690 \pm 74^{4}$ \\
\hline SOX & Ac & $29.1 \pm 0.6^{6,7,8}$ & $1717 \pm 34^{4}$ \\
\hline MAC & $\mathrm{Hx}$ & $17 \pm 1^{5}$ & $1937 \pm 57^{5,6}$ \\
\hline MAC & HxIPA & $17 \pm 4^{4,5}$ & $3765 \pm 98^{5,6}$ \\
\hline MAC & IPA & $38 \pm 1^{8}$ & $1440 \pm 6^{3}$ \\
\hline MAC & $\mathrm{EtOH}$ & $65.9 \pm 0.9^{8}$ & $736 \pm 5^{1}$ \\
\hline MAC & Ac & $58 \pm 1^{8}$ & $826 \pm 5^{2}$ \\
\hline UME & EtOH & $17 \pm 1^{5}$ & $2810 \pm 150^{5,6}$ \\
\hline OilH & Sun-oil & $8.4 \pm 0.7^{6,7}$ & $2684 \pm 23^{5}$ \\
\hline OilH & Soy oil & $7.0 \pm 0.5^{6}$ & $2256 \pm 25^{5}$ \\
\hline OilC & Sun-oil & $3 \pm 1^{6}$ & $3481 \pm 181^{6,7}$ \\
\hline OilC & Soy oil & $3.8 \pm 0.5^{6}$ & $4703 \pm 42^{6,7}$ \\
\hline SFE $313.15 \mathrm{~K} / 200 \mathrm{bar}$ & $\mathrm{CO}_{2}$ & $7.3 \pm 0.4^{2}$ & $6008 \pm 713^{8}$ \\
\hline SFE $333.15 \mathrm{~K} / 200 \mathrm{bar}$ & $\mathrm{CO}_{2}$ & $15 \pm 1^{5}$ & $2722 \pm 478^{5,6}$ \\
\hline SFE $313.15 \mathrm{~K} / 300 \mathrm{bar}$ & $\mathrm{CO}_{2}$ & $15 \pm 2^{5}$ & $2970 \pm 921^{5,6}$ \\
\hline SFE $333.15 \mathrm{~K} / 300 \mathrm{bar}$ & $\mathrm{CO}_{2}$ & $30 \pm 1^{6,7,8}$ & $1720 \pm 91^{4}$ \\
\hline SFE $333.15 \mathrm{~K} / 300 \mathrm{bar}$ & $\begin{array}{c}\mathrm{CO}_{2}+2 \% \\
\text { Sun-oil }\end{array}$ & $18 \pm 2^{5}$ & $2634 \pm 79^{5,6}$ \\
\hline SFE $333.15 \mathrm{~K} / 300 \mathrm{bar}$ & $\begin{array}{c}\mathrm{CO}_{2}+2 \% \\
\mathrm{Hx}: I P A\end{array}$ & $35 \pm 3^{6,7,8}$ & $1698 \pm 43^{4}$ \\
\hline
\end{tabular}

${ }^{\mathrm{a}} \mathrm{SOX}=$ Soxhlet, $\mathrm{MAC}=$ maceration; $\mathrm{UME}=$ ultrasonic maceration; OilH $=$ hot oil extraction; OilC $=$ cold oil extraction; $\mathrm{SFE}=$ supercritical fluid extraction; ${ }^{b} \mathrm{Hx}=$ hexane; HxIPA = hexane+isopropanol (50:50); IPA = isopropanol; $\mathrm{EtOH}=$ ethanol; $\mathrm{Ac}=$ acetone; Sun-oil $=$ sunflower oil; $\mathrm{CO}_{2}=$ carbon dioxide. 'Same superscript number in same column indicates no statistical difference $(\mathrm{p}<0.05)$. ${ }^{\mathrm{A}} \mathrm{AA}$ referent to DPPH method at extract concentration of $1000 \mu \mathrm{g} / \mathrm{mL}$; ${ }^{\mathrm{e}}$ Effective concentration at $50 \%$.

presented the highest antioxidant activity according to DPPH method were MAC-EtOH and MAC-Ac $(65.9 \% \pm$ $0.9 \%$ and $58 \% \pm 1 \%$, respectively), followed by the extracts MAC-IPA, SOX-EtOH and SOX-Ac (Table 1). In addition, the extracts MAC-EtOH and MAC-Ac presented the lowest effective concentration at $50 \%\left(\mathrm{EC}_{50}\right)$, i.e., $736 \pm 5$ and $826 \pm 5 \mu \mathrm{g} / \mathrm{mL}$, respectively. These values represent the extract concentration necessary to inhibit $50 \%$ of free radical activity. These results indicate that the antioxidant compounds presented in the pink shrimp residue present affinity to highly polar solvents (polarity between 5.1 and 5.2, according to Byers [20]). The good performance of the polar solvents in maceration method, applied to concentrate antioxidant compounds from natural products, was also observed by Kitzberger et al. [21] and by Almeida et al. [22], for the raw materials of shiitake and Mentha spicata, respectively.

The antioxidant activity performance of the extract obtained by vegetal oil extraction (OilC and $\mathrm{OilH}$ ) was determined considering the DPPH antioxidant results of the pure oils, i.e., the final results were obtained by the difference between pure oil and enriched oil results. According to the results presented in Table 1, the antioxidant activity values, by the DPPH method, obtained from the oily extracts (OilC and $\mathrm{OilH}$ ) were the lowest values compared to the results obtained for the other extraction methods. Nevertheless, the shrimp residue extract can be used to enrich the sunflower and soy oil in order to increase their shelf-life or to use the final product (enriched oils) in food formulations with antioxidant compounds incorporated.

When \%AA and $\mathrm{EC}_{50}$ results, obtained by DPPH method, were related to heat application in different systems used to the extraction, two contradictory behaviors were observed (Table 1): a) the high temperatures (equivalent to the solvent boiling temperature) used in the SOX method can damage the extraction of antioxidant components, compared to the same solvents used in MAC extraction (low temperature method); b) higher temperatures in vegetal oil extraction, by the OilH method, promoted higher \%AA when compared to the OilC method. These results can indicates that the antioxidant compounds presented in shrimp processing residue are better extracted when heat is applied until $343.15 \mathrm{~K}$, however the heating exposure should not be prolonged above 2 hour as for OilH systems. When higher temperatures and/ or heating exposure times are employed, the antioxidant compounds may suffer thermal degradation with the increasing temperature [23], a phenomenon that probably occurred for the samples obtained by the SOX extraction.

The DPPH results for the samples obtained by SFE process are also listed in Table 1, which shows that the extracts obtained by SFE at $333.15 \mathrm{~K} / 300$ bar, with $\mathrm{CO}_{2}$ and with $\mathrm{CO}_{2}$ plus Hx:IPA, presented the highest antioxidant activity values, statistically similar to SOX-EtOH and SOX-Ac extracts. The DPPH results for SFE extracts indicated that the \%AA increased significantly with the pressure enhancement, from 200 to $300 \mathrm{bar}$, at constant temperature, and with the temperature increase, from 313.15 to $333.15 \mathrm{~K}$, at constant pressure. This behavior is probably associated with the higher content of astaxanthin in shrimp residue extract obtained by SFE at higher pressures and temperatures [17]. According to Shimidzu et al. [24], the astaxanthin compounds present proved antioxidant properties. Also, the astaxanthin components are more soluble in supercritical $\mathrm{CO}_{2}$ when higher pres- 
sure and temperature are applied in the supercritical technology $[2,25]$.

The results of the \%AA determined by the $\beta$-carotene bleaching method are presented in Table 2, and were similar to the data from DPPH method, where the highest $\%$ AA values were obtained by polar solvents for the extract obtained at low pressure procedures. Alternatively, the $\beta$-carotene results were higher than the DPPH values, for all extracts analyzed, with highest results from the extracts by SOX-Ac, MAC-Ac, MAC-EtOH and SOX-IPA, equivalent to $88 \pm 3,84 \pm 1,82 \pm 2$ and $76.56 \% \pm 0.08 \%$, respectively (Table 2). These results are close to the $\%$ AA value obtained by the BHT $(113 \% \pm 7 \%)$ performance, as described by Benelli et al. [26], in the same conditions evaluated in the present work. The highest potential obtained by the $\beta$-carotene bleaching method above the DPPH is probably due to the presence of astaxanthin in these extracts, besides other antioxidant non-polar compounds, that are better detectable by the carotenoic method.

Similarly to the DPPH method, the $\beta$-carotene results from the extract obtained by vegetal oil extraction (OilC and $\mathrm{OilH}$ ) were determined considering the $\% \mathrm{AA}$ of pure oils. Among the oil extraction results from Table 2 we observe that the most efficient system was the OilH-sunflower, statistically equal to SOX-Hx, SOX-EtOH, and SFE at 200 bar, corroborating the previous suggestion about the use of this extract to increase the vegetal oil shelf-life and/or to enrich the antioxidant content when using it in food processing.

The SFE extracts also presented significant results of $\% \mathrm{AA}$ from the $\beta$-carotene bleaching method. The highest value was observed for the extracts obtained at 313.15 and $333.15 \mathrm{~K} / 300$ bar using pure $\mathrm{CO}_{2}$ and when it was added to $2 \%$ of Hx:IPA. Because of the satisfactory $\% \mathrm{AA}$ detected by the $\beta$-carotene bleaching method, we suggest the use of the mentioned extract, properly encapsulated/stabilized [27], in pharmaceutical or food products in order to prevent oxidant reactions.

\subsection{Antioxidant Activity of Grape Pomaces Extracts}

The $\mathrm{EC}_{50}$ values that represent the extract concentration necessary to inhibit $50 \%$ of free DPPH radical activity and the antioxidant activity (\%AA) results, determined by the $\beta$-carotene bleaching method, for the Merlot and Syrah grape pomaces extracts are showed in Table 3.

Concerning the $\mathrm{EC}_{50}$ achieved by the DPPH method, the SOX/EtOH Syrah extract showed the best result, meaning lowest value $(158 \pm 2 \mu \mathrm{g} / \mathrm{mL})$. All low pressure extractions with ethanol, for both grape varietals, presented low $\mathrm{EC}_{50}$ values, statistically equal to BHT [26]. The extracts obtained with low polar solvents presented
Table 2. Antioxidant activity (\%AA) obtained by the $\beta$-carotene bleaching method of shrimp ( $P$. brasiliensis and $P$. paulensis) residue extracts.

\begin{tabular}{|c|c|c|}
\hline Extraction method ${ }^{\mathrm{a}}$ & Solvent ${ }^{\mathrm{b}}$ & $\%$ AA $(120 \mathrm{~min})^{\mathrm{cd}}$ \\
\hline SOX & $\mathrm{Hx}$ & $57 \pm 4^{4,5}$ \\
\hline SOX & HxIPA & $68 \pm 7^{2,3,4}$ \\
\hline SOX & IPA & $76.56 \pm 0.08^{1,2,3}$ \\
\hline SOX & $\mathrm{EtOH}$ & $59 \pm 3^{4,5}$ \\
\hline SOX & Ac & $88 \pm 3^{1}$ \\
\hline MAC & $\mathrm{Hx}$ & $69 \pm 6^{2,3,4}$ \\
\hline MAC & HxIPA & $28 \pm 5^{7,8}$ \\
\hline MAC & IPA & $31 \pm 6^{7,8}$ \\
\hline MAC & $\mathrm{EtOH}$ & $82 \pm 2^{1,2}$ \\
\hline MAC & Ac & $84 \pm 1^{1,2}$ \\
\hline UME & $\mathrm{EtOH}$ & $38 \pm 5^{6,7}$ \\
\hline OilH & Sun-oil & $50 \pm 3^{5,6}$ \\
\hline OilH & Soy oil & $8 \pm 1^{9}$ \\
\hline OilC & Sun-oil & $16 \pm 2^{8,9}$ \\
\hline OilC & Soy oil & $2.8 \pm 0.6^{9}$ \\
\hline SFE $313.15 \mathrm{~K} / 200 \mathrm{bar}$ & $\mathrm{CO}_{2}$ & $50.2 \pm 0.9^{5,6}$ \\
\hline SFE $333.15 \mathrm{~K} / 200 \mathrm{bar}$ & $\mathrm{CO}_{2}$ & $59 \pm 7^{4,5}$ \\
\hline SFE $313.15 \mathrm{~K} / 300 \mathrm{bar}$ & $\mathrm{CO}_{2}$ & $87 \pm 4^{1}$ \\
\hline SFE $333.15 \mathrm{~K} / 300 \mathrm{bar}$ & $\mathrm{CO}_{2}$ & $72 \pm 6^{1,2,3,4}$ \\
\hline SFE $333.15 \mathrm{~K} / 300 \mathrm{bar}$ & $\mathrm{CO}_{2}+2 \%$ Sun-oil & $69 \pm 3^{2,3,4}$ \\
\hline SFE $333.15 \mathrm{~K} / 300 \mathrm{bar}$ & $\mathrm{CO}_{2}+2 \% \mathrm{Hx}: \mathrm{IPA}$ & $83 \pm 3^{1,2}$ \\
\hline
\end{tabular}

${ }^{\mathrm{a}} \mathrm{SOX}=$ Soxhlet $; \mathrm{MAC}=$ maceration $; \mathrm{UME}=$ ultrasonic maceration; $\mathrm{OilH}=$ hot oil extraction; OilC = cold oil extraction; SFE = supercritical fluid extraction; ${ }^{b} \mathrm{Hx}=$ hexane; HxIPA = hexane + isopropanol (50:50); IPA = isopropanol; $\mathrm{EtOH}=$ ethanol; $\mathrm{Ac}=$ acetone; Sun-oil $=$ sunflower oil; $\mathrm{CO}_{2}=$ carbon dioxide. ${ }^{\mathrm{c}}$ Same superscript number in same column indicates no statistical difference $(\mathrm{p}<0.05) ;{ }^{\mathrm{c}} \mathrm{AA}$ referent to $\beta$-carotene bleaching method obtained after 120 min-reaction at extract concentration of 1667 $\mu \mathrm{g} / \mathrm{mL}$.

$\mathrm{EC}_{50}$ results above $250 \mu \mathrm{g} / \mathrm{mL}$, a reference value from literature that represents low antioxidant potential [13]. Campos et al. [13] reported lower $\mathrm{EC}_{50}$ value for $\mathrm{SOX} /$ EtOH extract from Cabernet Sauvignon pomace and also results above $250 \mu \mathrm{g} / \mathrm{mL}$ for the supercritical extracts.

Based on the performance of low pressure ethanolic extracts, EtOH was used as co-solvent in the SFE, improving the DPPH results but still being above 250 $\mu \mathrm{g} / \mathrm{mL}$. In the $\beta$-carotene bleaching method results, the addition of EtOH to $\mathrm{CO}_{2}$ on SFE did not reflected in better results remaining statistically equal to the ones obtained with pure $\mathrm{CO}_{2}$. 
Table 3. Effective concentration at $\mathbf{5 0} \%$ antioxidant activity $\left(E_{50}\right)$ obtained by the free radical scavenging activity method (DPPH) and the antioxidant activity (\%AA) obtained by the $\beta$-carotene bleaching method of Merlot and Syrah grape (Vitis vinifera) pomaces extracts.

\begin{tabular}{|c|c|c|c|c|}
\hline Extraction $^{\mathrm{a}}$ & Solvent $^{\mathrm{b}}$ & Grape & $\begin{array}{c}E_{50} \\
(\mu \mathrm{g} / \mathrm{mL})^{\mathrm{cd}}\end{array}$ & $\begin{array}{c}\text { \%AA } \\
(120 \text { min })^{\text {ce }} \\
\end{array}$ \\
\hline SOX & HX & Syrah & $2684 \pm 233^{6,7}$ & $29.2 \pm 0.6^{4,5,6}$ \\
\hline SOX & EtOAc & Syrah & $680 \pm 21^{1,2}$ & NT \\
\hline SOX & $\mathrm{EtOH}$ & Syrah & $158 \pm 2^{1}$ & $4.4 \pm 0.8^{8}$ \\
\hline SOX & HX & Merlot & $9299 \pm 44^{13}$ & $45.7 \pm 0.3^{3}$ \\
\hline SOX & EtOAc & Merlot & $600 \pm 16^{1}$ & NT \\
\hline SOX & $\mathrm{EtOH}$ & Merlot & $208 \pm 2^{1}$ & $46 \pm 3^{3}$ \\
\hline UME & HX & Syrah & $2618 \pm 112^{6,7}$ & $15 \pm 1^{6,7,8}$ \\
\hline UME & EtOAc & Syrah & $1493 \pm 148^{3,4}$ & NT \\
\hline UME & $\mathrm{EtOH}$ & Syrah & $211 \pm 2^{1}$ & $20.0 \pm 0.7^{5,6,7}$ \\
\hline UME & $\mathrm{H}_{2} \mathrm{O}$ & Syrah & $346 \pm 27^{1}$ & $20 \pm 1^{5,6}$ \\
\hline UME & HX & Merlot & $4097 \pm 2^{9,10,11}$ & $61.7 \pm 0^{2}$ \\
\hline UME & EtOAc & Merlot & $1402 \pm 59^{3}$ & NT \\
\hline UME & $\mathrm{EtOH}$ & Merlot & $394 \pm 5^{1}$ & $61 \pm 2^{2}$ \\
\hline UME & $\mathrm{H}_{2} \mathrm{O}$ & Merlot & $1321 \pm 129^{2,3}$ & $4.4 \pm 0.3^{8}$ \\
\hline $\begin{array}{l}\text { SFE } 323.15 \mathrm{~K} / \\
150 \mathrm{bar}\end{array}$ & $\mathrm{CO}_{2}$ & Merlot & $5770 \pm 240^{13}$ & $66 \pm 2^{2}$ \\
\hline $\begin{array}{l}\text { SFE } 323.15 \mathrm{~K} / \\
200 \mathrm{bar}\end{array}$ & $\mathrm{CO}_{2}$ & Merlot & $4471 \pm 58^{10,11}$ & $27 \pm 2^{4,5,6}$ \\
\hline $\begin{array}{l}\text { SFE } 323.15 \mathrm{~K} / \\
250 \mathrm{bar}\end{array}$ & $\mathrm{CO}_{2}$ & Merlot & $5508 \pm 213^{12,13}$ & $24 \pm 3^{4,5,6}$ \\
\hline $\begin{array}{l}\text { SFE } 323.15 \mathrm{~K} / \\
300 \mathrm{bar}\end{array}$ & $\mathrm{CO}_{2}$ & Merlot & $5161 \pm 186^{12,13}$ & $23.6 \pm 0.6^{4,5,6}$ \\
\hline $\begin{array}{c}\text { SFE } 333.15 \mathrm{~K} / \\
150 \mathrm{bar}\end{array}$ & $\mathrm{CO}_{2}$ & Merlot & $2349 \pm 57^{5,6,7}$ & $45 \pm 1^{3}$ \\
\hline $\begin{array}{l}\text { SFE } 333.15 \mathrm{~K} / \\
200 \mathrm{bar}\end{array}$ & $\mathrm{CO}_{2}$ & Merlot & $3528 \pm 123^{8,9}$ & $27 \pm 2^{4,5,6}$ \\
\hline $\begin{array}{l}\text { SFE } 333.15 \mathrm{~K} / \\
250 \mathrm{bar}\end{array}$ & $\mathrm{CO}_{2}$ & Merlot & $2917 \pm 97^{7,8}$ & $32.18 \pm 0^{3,4,5}$ \\
\hline $\begin{array}{l}\text { SFE } 333.15 \mathrm{~K} / \\
300 \mathrm{bar}\end{array}$ & $\mathrm{CO}_{2}$ & Merlot & $3814 \pm 157^{9,10}$ & $45 \pm 6^{3}$ \\
\hline $\begin{array}{l}\text { SFE } 333.15 \mathrm{~K} / \\
250 \mathrm{bar}\end{array}$ & $\begin{array}{c}\mathrm{CO}_{2}+12.5 \% \\
\text { EtOH }\end{array}$ & Merlot & $1772 \pm 98^{3,4,5}$ & $23 \pm 4^{4,5,6}$ \\
\hline $\begin{array}{l}\text { SFE } 333.15 \mathrm{~K} / \\
250 \mathrm{bar}\end{array}$ & $\begin{array}{c}\mathrm{CO}_{2}+15 \% \\
\text { EtOH }\end{array}$ & Merlot & $2143 \pm 88^{4,5,6}$ & $26 \pm 5^{4,5,6}$ \\
\hline $\begin{array}{l}\text { SFE } 333.15 \mathrm{~K} / \\
250 \mathrm{bar}\end{array}$ & $\begin{array}{c}\mathrm{CO}_{2}+17.5 \% \\
\mathrm{EtOH}\end{array}$ & Merlot & $1501 \pm 72^{3,4}$ & $35 \pm 2^{3,4}$ \\
\hline $\begin{array}{l}\text { SFE } 333.15 \mathrm{~K} / \\
250 \mathrm{bar}\end{array}$ & $\mathrm{CO}_{2}$ & Syrah & $4788 \pm 258^{11,12}$ & $23 \pm 2^{4,5,6}$ \\
\hline BHT & - & - & $261 \pm 12^{1}$ & $113 \pm 7^{1}$ \\
\hline
\end{tabular}

${ }^{\mathrm{a}} \mathrm{SOX}=$ Soxhlet; $\mathrm{UME}=$ ultrasonic maceration; $\mathrm{SFE}=$ supercritical fluid extraction. ${ }^{\text {b }} \mathrm{Hx}=$ hexane; EtOAc = ethyl acetate; $\mathrm{EtOH}=$ ethanol; $\mathrm{H}_{2} \mathrm{O}=$ water; $\mathrm{CO}_{2}=$ carbon dioxide. ${ }^{\mathrm{c}} \mathrm{Same}$ superescript number in same column indicates no statistical difference $(\mathrm{p}<0.05)$; ${ }^{\mathrm{d}}$ Effective concentration at $50 \%$ AA referent to DPPH method. ${ }^{\mathrm{e}} \mathrm{AA}$ referent to $\beta$-carotene bleaching method obtained after 120 min-reaction at extract concentration of $1667 \mu \mathrm{g} / \mathrm{mL}$. NT $=$ not tested.
The $\beta$-carotene bleaching method is more appropriate to analyze lipid fractions, what can explain the highest antioxidant activity (\%AA) presented by the Merlot extract obtained with pure supercritical $\mathrm{CO}_{2}$ at $150 \mathrm{bar} /$ $323.15 \mathrm{~K}(66 \% \pm 2 \%)$ and with $\mathrm{UME} / \mathrm{Hx}(61.7 \% \pm 0 \%)$, but still low compared to BHT $(113 \% \pm 7 \%)$. Jayaprakasha et al. [9] reported higher \%AA values (up to $88.7 \%$ ) for SOX extraction with methanol form Bangalore defatted grape seed. The Merlot extracts obtained with EtOH (polar) presented similar \%AA results to the non polar solvents, affirming it as the best solvent tested. This could be expected as red grapes are known by their high content of phenolic compounds which are polar substances [12].

On the SFE results from both grape cultivars no tendency with pressure, temperature or solvent density is observed.

Analyzing the grape varietal influence by comparing each extraction method and solvent, in general no significant difference can be pointed on DPPH results. However, the Merlot cultivar presented better \%AA values in $\beta$-carotene method.

Based on the good $\mathrm{EC}_{50}$ value detected on the Merlot ethanolic extracts and on the high reactivity of phenolic compounds (degradation with light and oxygen exposure) [28], we believe that the encapsulation/stabilization of the mentioned extract can enable its use in pharmaceutical or food products in order to prevent oxidant reactions.

\section{Conclusions}

The study of the antioxidant activity from shrimp residue extracts revealed that the highest antioxidant activities, determined by the DPPH and $\beta$-carotene methods, were observed in extracts obtained by polar solvents. In addition, among the different supercritical conditions, the extract obtained at 300 bar and $333.15 \mathrm{~K}$ presented antioxidant activity by $\beta$-carotene bleaching method is similar to some low pressure extracts and to the BHT standard. The $\beta$-carotene bleaching method showed superior antioxidant results compared to the DPPH method, indicating that: the $\beta$-carotene system is more sensitive to the chemical characteristics of the shrimp residue extracts (presence of non-polar antioxidant compounds).

The use of grape pomace is promising due to the importance of the substances that remain in this industrial residue such as antioxidant compounds. Extracts obtained by low pressure techniques with polar solvents, notably the extracts obtained by Sohxlet with ethanol from both grapes, showed the lowest concentration that neutralizes $50 \%$ of free DPPH radicals $\left(\mathrm{EC}_{50}\right)$. The SFE with pure $\mathrm{CO}_{2}$ at $323.15 \mathrm{~K} / 150$ bar on the Merlot pomace led to the extract with best antioxidant activity determined by the $\beta$-carotene bleaching method, followed by low pressure Merlot extracts obtained with ethanol and hexane. In 
general, the Merlot cultivar presented better performance than the Syrah varietal.

\section{Acknowledgements}

The authors wish to thank Capes for the doctoral fellowship, CNPq (470862/2010-6) for the financial support, Peixaria Nelson Santos and Miolo Wine Group for the raw material supply (shrimp processing residue and grape pomaces respectively).

\section{REFERENCES}

[1] FAO-Food and Agriculture Organization of United Nations, "Statistics of World Production in Fishing, year of 2007," FISHSTAT, Rome, 2008.

[2] N. Mezzomo, B. Maestri, R. L. dos Santos, M. Maraschin and S. R. S. Ferreira, "Pink Shrimp (P. brasiliensis and $P$. paulensis) Processing Residue: Influence of Extraction Method on Carotenoid Concentration," Talanta, Vol. 85, No. 3, 2011, pp. 1383-1391. doi:10.1016/j.talanta.2011.06.018

[3] A. A. S. Brum, M. Oetterer, M. A. B. Regitano-D'Arce, "Óleo de Pescado Como Suplemento Dietético," Revista Ciência \& Tecnologia, Vol. 10, No. 19, 2002, pp. 71-78.

[4] Z.-C. Hu, Y.-O. Zheng, Z. Wang and Y.-C. Shen, "pH Control Strategy in Astaxanthin Fermentation Bioprocess by Xanthophyllomyces dendrorhous," Enzyme and Microbial Technology, Vol. 39, No. 4, 2006, pp. 586-590. doi:10.1016/j.enzmictec.2005.11.017

[5] O. Takahashi and K. Hiraga, "Dose-Response Study of Hemorrhagic Death by Dietary Butylated Hydroxytoluene (BHT) in Male Rats," Toxicology and Applied Pharmacology, Vol. 43, No. 2, 1978, pp. 399-406. doi:10.1016/0041-008X(78)90019-4

[6] H. Witschi and S. Lock, "Toxicity of Butylated Hydroxytoluene in Mouse Following Oral Administration," Toxicology, Vol. 9, No. 1-2, 1978, pp. 137-146. doi:10.1016/0300-483X(78)90038-0

[7] J. A. Passoto, M. V. C. Penteado and J. Mancini-Filho, "Atividade Antioxidante Do B-Caroteno e da Vitamina A. Estudo Comparativo com Antioxidante Sintético," Ciência e Tecnologia de Alimentos, Vol. 18, No. 1, 1998, pp. 68-72. doi:10.1590/S0101-20611998000100015

[8] M. Pinelo, A. Arnous and A. S. Meyer, "Upgrading of Grape Skins: Significance of Plant Cell-Wall Structural Components and Extraction Techniques for Phenol Release," Trends in Food Science \& Technology, Vol. 17, No. 11, 2006, pp. 579-590. doi:10.1016/j.tifs.2006.05.003

[9] G. K. Jayaprakasha, R. P. Singh and K. K. Sakariah, "Antioxidant Activity of Grape Seed (Vitis Vinifera) Extracts on Peroxidation Models in Vitro," Food Chemistry, Vol. 73, No. 3, 2001, pp. 285-290. doi:10.1016/S0308-8146(00)00298-3

[10] C. Negro, L. Tommasi and A. Miceli, "Phenolic Compounds and Antioxidant Activity from Red Grape Marc Extracts," Bioresource Technology, Vol. 87, No. 1, 2003, pp. 41-44. doi:10.1016/S0960-8524(02)00202-X

[11] V. Filip, M. Plocková, J. Šmidrkal, Z. Špicková, K. Melzoch and Š. Schmidt, "Resveratrol and Its Antioxidant and Antimicrobial Effectiveness," Food Chemistry, Vol. 83, No. 4, 2003, pp. 585-593. doi:10.1016/S0308-8146(03)00157-2

[12] P. L. Teissedre, E. N. Frankel, A. L. Waterhouse, H. Peleg and J. B. German, "Inhibition of in Vitro Human LDL Oxidation by Phenolic Antioxidants from Grapes and Wines," Journal of the Science of Food and Agriculture, Vol. 70, No. 1, 1996, pp. 55-61. doi:10.1002/(SICI)1097-0010(199601)70:1<55::AID-JSF A471>3.0.CO;2-X

[13] L. M. A. S. Campos, F. V. Leimann, R. C. Pedrosa and S. R. S. Ferreira, "Free Radical Scavenging of Grape Pomace Extracts from Cabernet Sauvingnon (Vitis vinifera)," Bioresource Technology, Vol. 99, No. 17, 2008, pp. 84138420. doi:10.1016/j.biortech.2008.02.058

[14] N. M. Sachindra and N. S. Mahendrakar, "Process Optimization for Extraction of Carotenoids from Shrimp Waste with Vegetable Oils," Bioresource Technology, Vol. 96, No. 10, 2005, pp. 1195-1200.

doi:10.1016/j.biortech.2004.09.018

[15] C. Zetzl, G. Brunner and M. A. A. Meireles, "Standardized Low-Cost Batch SFE Units for University Education and Comparative Research," Proceedings of the 6th International Symposium on Supercritical Fluids, 28-30 April 2003, pp. 577-581.

[16] E. M. Z. Michielin, L. F. V. Bresciani, L. Danielski, R. A. Yunes and S. R. S. Ferreira, "Composition Profile of Horsetail (Equisetum giganteum L.) Oleoresin: Comparing SFE and Organic Solvents Extraction," Journal of Supercritical Fluids, Vol. 33, No. 2, 2005, pp. 131-138. doi:10.1016/j.supflu.2004.07.004

[17] N. Mezzomo, J. Martínez, M. Maraschin and S. R. S. Ferreira, "Pink Shrimp (P. brasiliensis and P. paulensis) Residue: Supercritical Fluid Extraction of Carotenoid Fraction," The Journal of Supercritical Fluids, Vol. 74, 2013, pp. 22-33. doi:10.1016/j.supflu.2012.11.020

[18] L. L. Mensor, F. S. Menezes, G. G. Leitão, A. S. Reis, T. C. dos Santos, C. S. Coube and S. G. Leitão, "Screening of Brazilian Plant Extracts for Antioxidant Activity by the Use of DPPH Free Radical Method," Phitotherapy Research, Vol. 15, No. 2, 2001, pp. 127-130. doi: $10.1002 / \mathrm{ptr} .687$

[19] B. Matthäus, "Antioxidant Activity of Extracts Obtained from Residues of Different Oilseeds," Journal Agriculture Food Chemistry, Vol. 50, No. 12, 2002, pp. 3444 3452. doi:10.1021/jf011440s

[20] J. A. Byers, "Phenomenex Catalog," 2009. http://www.phenomenex.com/phen/Doc/z366.pdf

[21] C. S. G. Kitzberger, A. Smânia Jr., R. C. Pedrosa and S. R. S. Ferreira, "Antioxidant and Antimicrobial Activities of Shiitake (Lentinula edodes) Extracts Obtained by Organic Solvents and Supercritical Fluids," The Journal of Food Engineering, Vol. 80, No. 2, 2007, pp. 631-638. doi:10.1016/j.jfoodeng.2006.06.013

[22] P. P. Almeida, N. Mezzomo and S. R. S. Ferreira, "Extraction of Mentha spicata L. Volatile Compounds: Eva- 
luation of Process Parameters and Extract Composition," Food and Bioprocess Technology, Vol. 5, No. 2, 2012, pp. 548-559. doi:10.1007/s11947-010-0356-y

[23] Q. Hu, Y. Hu and J. Xu, "Free Radical-Scavenging Activity of Aloe Vera (Aloe barbadensis Miller) Extracts by Supercritical Carbon Dioxide Extraction," Food Chemistry, Vol. 91, No. 1, 2005, pp. 85-90. doi:10.1016/j.foodchem.2004.05.052

[24] N. Shimidzu, M. Goto and W. Miki, "Carotenoids as Singlet Oxygen Quenchers in Marine Organisms," Fisheries Science, Vol. 62, No. 1, 1996, pp. 134-137.

[25] J. C. La Fuente, B. Oyarzún, N. Quezada and J. M. Valle, "Solubility of Carotenoid Pigments (Lycopene and Astaxanthin) in Supercritical Carbon Dioxide," Fluid Phase Equilibria, Vol. 247, No. 1-2, 2006, pp. 90-95. doi:10.1016/j.fluid.2006.05.031

[26] P. Benelli, C. A. S. Riehl, A. Smânia Jr., E. F. A. Smânia and S. R. S. Ferreira, "Bioactive Extracts of Orange (Citrus sinensis L. Osbeck) Pomace Obtained by SFE and Low Pressure Techniques: Mathematical Modeling and Extract Composition," The Journal of Supercritical Fluids, Vol. 55, No. 1, 2010, pp. 132-140. doi:10.1016/j.supflu.2010.08.015

[27] N. Mezzomo, E. De Paz, A. Martín, M. J. Cocero and S. R. S Ferreira, "Supercritical Anti-Solvent Precipitation of Carotenoid Fraction from Pink Shrimp Residue: Effect of Operational Conditions on Encapsulation Efficiency," The Journal of Supercritical Fluids, Vol. 66, 2012, pp. 342-349. doi:10.1016/j.supflu.2011.08.006

[28] M. Pinelo, P. Del Fabbro, L. Manzocco, M. J. Nuñez and M. C. Nicoli, "Optimization of Continuous Phenol Extraction from Vitis vinifera Byproducts," Food Chemistry, Vol. 92, No. 1, 2005, pp. 109-117. doi:10.1016/j.foodchem.2004.07.015 